\title{
A novel perylene diimide-based tetrahedral molecule: Synthesis, characterization and self-assembly with gold nanoparticles
}

\author{
JUN-BO LI ${ }^{1, *}$, XIANG-LIN YU², JING FU², XIWEN LIU² and YANG ZENG ${ }^{2}$ \\ ${ }^{1}$ Hubei Novel Reactor and Green Chemical Technology Key Laboratory, Key Laboratory for Green \\ Chemical Process of Ministry of Education, Wuhan Institute of Technology, China \\ ${ }^{2}$ Department of Chemical Engineering and Pharmacy, Wuhan Institute of Technology, Wuhan, \\ Hubei Province, China \\ e-mail: jbli@mail.wit.edu.cn
}

MS received 18 November 2009; revised 16 March 2010; accepted 2 September 2010

\begin{abstract}
In this study, a novel tetrahedral molecule TPPY was successfully designed and synthesized. The self-assembly of TPPY with gold nanoparticles (Au NPs) in toluene has also been investigated. The aggregation morphologies of Au NPs can be controlled to produce different aggregate structures by changing the concentration of ligand TPPY.
\end{abstract}

Keywords. Gold nanoparticles; perylene diimide; self-assembly; aggregation.

\section{Introduction}

Recently, much attention has been focused on the perylene diimide-based red chromophores, due to their unique chemical, thermal, and photochemical stability. These chromophores show various possible applications in fluorescent solar collectors ${ }^{1}$, light emitting diodes ${ }^{2}$, dye lasers ${ }^{3,4}$, molecular switches ${ }^{5}$, and photovoltaic devices. ${ }^{6-8}$ They are highly absorbing in the visible to near-IR region $\left(\varepsilon \approx 10^{5} \mathrm{M}^{-1} \mathrm{~cm}^{-1}\right)$ and emit fluorescene with quantum yields near unity. ${ }^{9,10}$ Perylene based chromophoric arrays ${ }^{11,12}$ are promising components for the construction of optical and electronic molecular devices. ${ }^{13,14}$

The ability to assemble nanoparticles with controllable size and shape ${ }^{15-21}$ is of great interest, due to their potential applications in sensors ${ }^{22-26}$ catalysts $^{27,28}$ and optoelectronic nanodevices. ${ }^{29-35}$ The controllable size, shape and properties of the individual nanoparticle building blocks via self-assembly combining with the properties of organic molecules on the gold surface lead to the enhancement of device properties. $^{36,37}$ Nowadays, the chromophores such as porphyrin, ${ }^{38,39}$ fullerene, ${ }^{40-42} \mathrm{OPV}^{43}$ based molecules assembling with the gold nanoparticles (Au NPs) have been reported widely. ${ }^{44,45}$ However, only few literatures have been reported on the perylene diimide based chromophores assembling with them. ${ }^{46}$

\footnotetext{
*For correspondence
}

Comparing to the flexible linkers, the rigid linkers are easier to control the uniformity of Au NPs aggregation. For example, Andres et al. ${ }^{47}$ have obtained an equal distance aggregation of Au NPs by a rigid molecule of aryl di-isonitrile [1,4-di(4-isocyanophenylethynyl)-2-ethylbenzene]; Chen et al. ${ }^{48}$ have prepared a Au-MPCs based two-dimensional film with a rigid molecule 4,4'-thiobisbenzenethiol. In this paper, we report the controlling of the self-assembly of Au NPs with a rigid molecule TPPY. The tetrahedral structure of TPPY can prohibit $\pi-\pi$ stacking of perylenetetracarboxylic acid diimide. When TPPY assembled with the Au NPs, the strong $\pi-\pi$ stacking of perylene unit was prohibited, which suggested the aggregation of Au NPs was only influenced by the structure of TPPY. Although the coordination of pyridine with the surface of Au NPs is weaker than that of thiols, this relative weak coordination might be useful in the reversible aggregation of $\mathrm{Au}$ NPs. ${ }^{47}$ The controlled aggregation of perylenetetracarboxylic acid diimide derivatives protected $\mathrm{Au}$ NPs is useful for the construction of nanoparticles-based photovoltaic devices in the future.

\section{Experimental}

\subsection{Materials and methods}

All solvents were purified according to standard procedures. Reactions were monitored by thin-layer 
chromatography on glass plates coated with $\mathrm{SiO}_{2}$ F254. The plates were inspected by UV light or in $I_{2}$ vapor. Column chromatography was performed on silica gel (160-200 mesh). ${ }^{1} \mathrm{H}$ and ${ }^{13} \mathrm{C}$ NMR spectra were recorded on Bruker AV 400 (400 and $100 \mathrm{MHz}$, respectively) at ambient temperature. They were referenced using their residual solvent as the internal standard. The chemical shift values were expressed as $\delta$ values, and the coupling constants values $(J)$ are in Hertz. The following abbreviations were used for signal multiplicities: s singlet; $d$ doublet; $t$ triplet; $m$ multiplet. Matrix-assisted laser desorption ionization time-of flight (MALDI-TOF) mass spectra were performed on Bruker Biflex III MALDI-TOF spectrometer. The UV/Vis spectra of $\mathrm{Au}$ NPs colloid before and after ligand exchange were measured at room temperature by a Hitachi U-3010 spectrophotometer. Fluorescence spectra were obtained on Hitachi F-4500 fluorimeter. TEM micrographs were taken from JEOL JEM-1011 microscope with an acceleration voltage of $100 \mathrm{kV}$. The samples were prepared by dropping the corresponding solution of $\mathrm{Au}$ NPs onto carbon-coated copper grids.

\subsection{Synthetic procedures of TPPY and TPOT}

2.2a Synthesis of $N$-[1-(4-pyridyl)methyl]-1, 6, 7, 12-tetra(4-tert-butylphenoxy)-perylene-3,4-anhydride9, 10-tetracarboxylic Imide (4): 1, 6, 7, 12-tetra(4tert-butylphenoxy)-perylene-3,4,9,10-tetracarboxylic Bisanhydride (2) $(0.50 \mathrm{~g}, 0.5 \mathrm{mmol}), 4$-(aminomethyl)pyridine $(11 \mu \mathrm{L}, 0.1 \mathrm{mmol})$, and imidazole $(200 \mathrm{mg})$ were stirred in toluene $(30 \mathrm{~mL})$ under argon at reflux for $2 \mathrm{~h}$. The reaction mixture was washed with water twice and then dried over anhydrous sodium sulphate. The solvent was removed in vacuo and the residue was then purified by silica gel chromatography with $\mathrm{CH}_{2} \mathrm{Cl}_{2} /$ methanol $(70: 1)$ as eluant to afford the title compound (80 mg, 74\% yield). ${ }^{1} \mathrm{H}$ NMR $\left(400 \mathrm{MHz}, \mathrm{CDCl}_{3}\right.$ ), $\delta 8.52(s, 2 \mathrm{H}), 8.21-8.26(m, 4 \mathrm{H}), 7.31(d, 2 \mathrm{H}$, $J=4.0 \mathrm{~Hz}), 7.25(d, 8 \mathrm{H}, J=8.5 \mathrm{~Hz}), 6.81-6.83(m$, $8 \mathrm{H}), 5.30(s, 2 \mathrm{H}), 1.65(m, 8 \mathrm{H}), 1.25-1.29(\mathrm{~m}, 36 \mathrm{H})$. ${ }^{13} \mathrm{C}$ NMR $\left(100 \mathrm{MHz}, \mathrm{CDCl}_{3}\right) \delta 31.5,34.4,42 \cdot 9$, $118.2,119.3,119.5,119.8,112 \cdot 0,120 \cdot 2,120 \cdot 3$, $120 \cdot 6,121 \cdot 1,121 \cdot 5,121 \cdot 6,121 \cdot 7,121 \cdot 9,122 \cdot 3$, $122 \cdot 6,123 \cdot 2,126 \cdot 7,126 \cdot 8,126 \cdot 9,132 \cdot 8,133 \cdot 0$, $133 \cdot 4,146 \cdot 0,146 \cdot 2,147 \cdot 4,147 \cdot 7,147 \cdot 8,149 \cdot 8$, $152 \cdot 5,152 \cdot 6,155 \cdot 8,156 \cdot 0,156 \cdot 5,159 \cdot 9,163 \cdot 2$, $163 \cdot 4$. 2.2b Synthesis of TPPY: Tetra(4-aminophenyl) methane (7) $(26 \mathrm{mg}, \quad 0.07 \mathrm{mmol}), 4 \quad(300 \mathrm{mg}$, $0.28 \mathrm{mmol})$, and imidazole $(150 \mathrm{mg})$ were stirred under argon at reflux for $3 d$ in toluene $(60 \mathrm{~mL})$. The reaction mixture was washed with water twice and then dried over anhydrous sodium sulphate. The solvent was removed in vacuo and the residue was then purified by silica gel chromatography with $\mathrm{CH}_{2} \mathrm{Cl}_{2}$ /methanol $(10: 1)$ as eluant to afford the title compound ( $150 \mathrm{mg}, 46 \%$ yield). ${ }^{1} \mathrm{H}$ NMR $\left(400 \mathrm{MHz}, \mathrm{CDCl}_{3}\right), \delta 8.51(d, 8 \mathrm{H}, J=4.9 \mathrm{~Hz}), 8.26$ $(s, 8 \mathrm{H}), 8 \cdot 18(s, 8 \mathrm{H}), 7 \cdot 31-7 \cdot 33(m, 16 \mathrm{H}), 7 \cdot 11-7 \cdot 26$ $(m, 40 \mathrm{H}), 6 \cdot 79-6.84(m, 32 \mathrm{H}), 5.30(\mathrm{brs}, 8 \mathrm{H}), 1.28$ $(s, 72 \mathrm{H}), 1.23(s, 72 \mathrm{H}) .{ }^{13} \mathrm{C}$ NMR $(100 \mathrm{MHz}$, $\left.\mathrm{CDCl}_{3}\right) \delta 31 \cdot 4,34 \cdot 4,42 \cdot 8,64 \cdot 5,119 \cdot 3,119 \cdot 4,119 \cdot 5$, $120 \cdot 0,120 \cdot 2,120 \cdot 4,121 \cdot 1,121 \cdot 8,122 \cdot 7,123 \cdot 1$, $126 \cdot 6,126 \cdot 7,127 \cdot 7,132 \cdot 1,133 \cdot 0,133 \cdot 1,133 \cdot 4$, $145.9,146 \cdot 2,147 \cdot 4,150 \cdot 0,152 \cdot 7,152 \cdot 8,155.9$, $156.3,163.4,163.5$. MALDI-TOF: calcd, 4609.4 [M] ${ }^{+}$, observed: $m / z$ 4609.6 [M] ${ }^{+}$, anal. Calcd. (\%) for $\mathrm{C}_{305} \mathrm{H}_{264} \mathrm{~N}_{12} \mathrm{O}_{32}: \mathrm{C}, 79.47 ; \mathrm{H}, 5.77 ; \mathrm{N}, 3.65$. Found: C, 79.43; H, 5.76; N, 3.71.

2.2c Synthesis of TPOT: Tetra(4-aminophenyl) methane (7) $(26 \mathrm{mg}, \quad 0.07 \mathrm{mmol}), 3 \quad(307 \mathrm{mg}$, $0.28 \mathrm{mmol})$, and imidazole $(150 \mathrm{mg})$ were stirred in toluene $(60 \mathrm{~mL})$ under argon at reflux for $3 d$. The reaction mixture was washed with water twice and then dried over anhydrous sodium sulphate. The solvent was removed in vacuo and the residue was then purified by silica gel chromatography with $\mathrm{CH}_{2} \mathrm{Cl}_{2}$ as eluant to afford the title compound (210 mg, 64\% yield). ${ }^{1} \mathrm{H}$ NMR ( $\left.400 \mathrm{MHz}, \mathrm{CDCl}_{3}\right), \delta$ $8.51(d, 8 \mathrm{H}, J=4.9 \mathrm{~Hz}), 8.24(s, 8 \mathrm{H}), 7.32(d, 8 \mathrm{H}$, $J=8.0 \mathrm{~Hz}), 7 \cdot 17-7.24 \quad(m, 32 \mathrm{H}), 7.11 \quad(d, 8 \mathrm{H}$, $J=8.0 \mathrm{~Hz}), 6 \cdot 79-6.84(\mathrm{~m}, 32 \mathrm{H}), 4 \cdot 10(\mathrm{brs}, 8 \mathrm{H})$, 0.83-1.67 $(\mathrm{m}, 212 \mathrm{H}),{ }^{13} \mathrm{C}$ NMR $\left(100 \mathrm{MHz}, \mathrm{CDCl}_{3}\right)$ $163.4,156 \cdot 0,155.9,152.9,152 \cdot 8,147 \cdot 2,147 \cdot 2$, $146 \cdot 2,133 \cdot 4,133 \cdot 0,132 \cdot 1,127 \cdot 7,126 \cdot 6,122 \cdot 5$, $120.6,120.5,120.0,119.9,119.7,119.4,119.4$, $119 \cdot 3,34 \cdot 3,34 \cdot 30,31 \cdot 8,31 \cdot 4,31 \cdot 4,29 \cdot 7,29 \cdot 3,29 \cdot 2$, $28 \cdot 1,27 \cdot 1,22 \cdot 6,14 \cdot 1$. MALDI-TOF: calcd. $4694 \cdot 4$ $[\mathrm{M}]^{+}$, observed: $m / z$ 4694.6 [M] $]^{+}$.

\subsection{Synthesis of TOAB-capped Au NPs}

The TOAB-capped Au NPs were prepared according to the reported method. ${ }^{46}$ Tetra-n-octylammonium bromide (TOAB) $(34.7 \mathrm{mg}$ in $0.67 \mathrm{~mL}$ of toluene) was added to a solution of $\mathrm{HAuCl}_{4} \cdot 4 \mathrm{H}_{2} \mathrm{O}(10 \mathrm{mg}$ in $0.33 \mathrm{~mL}$ of deionized water) and shaken in a separa- 
tory funnel. After the yellow water layer became colourless, the water layer was removed. The resulting solution was stirred vigorously in a $5 \mathrm{~mL}$ roundbottom flask while a freshly prepared solution (9.6 mg $\mathrm{NaBH}_{4}$ in $0.17 \mathrm{~mL}$ of deionized water) was added after which the solution became darkened. The water layer was removed by extraction after $4 \mathrm{~h}$ of stirring and then the toluene layer was washed for three times with deionized water $(1 \mathrm{~mL}$ for each time).

\subsection{Self-assembly of TPPY with TOAB-capped Au NPs}

The TPPY with different concentration in toluene was added to the $\mathrm{Au}$ NPs solution $(18.8 \mathrm{nM}$ and $0.47 \mu \mathrm{M})$ in the dark and stirred for $2 \mathrm{~min}$ at room temperature. The pyridine groups were allowed to undergo a place-exchange reaction with TOABcapped $\mathrm{Au}$ NPs. Then the UV-vis spectra were detected (delete the absorption of TPPY).

\section{Results and discussion}

3.1 Synthesis and characterization of the perylene diimide ligand TPPY and its derivative TPOT

The synthesis of TPPY and TPOT was shown in scheme $1 .{ }^{50,51}$ A mixture of 1,6,7,12-tetra(4-tertbutylphenoxy)-perylene-3,4,9,10-tetracarboxylic bisanhydride (2) and $N$-octyl-1,6,7,12-tetra(4-tertbutylphenoxy)-perylene-3,4-anhydride-9,10-tetracar boxylic imide (3) was obtained by partial saponification of the corresponding $N, N^{\prime}$-di(8-aminooctyl)-1,6,7,12-tetra(4-tert-butylphenoxy)-perylene3,4,9,10-tetracarboxylic diimide (1). $\quad N$-[1-(4pyridyl)methyl]-1,6,7,12-tetra(4-tert-butylphenoxy)perylene-3,4-anhydride-9,10-tetracarboxylic imide (4) was obtained by the imidization of compound 2 and 4-(aminomethyl)pyridine in toluene. ${ }^{52} \mathrm{Com}$ pounds of TPPY and TPOT were obtained by the same reaction of $\mathbf{4}$ and $\mathbf{3}$ with tetra(4-aminophenyl)methane (7) in toluene, respectively.

The optical absorption and fluorescence properties of the compounds TPPY and TPOT (figure 1) and the relative fluorescence quantum yield (table 1) were investigated. The absorption band of the perylene unit in compound TPOT showed the characteristic $\partial \partial$ transitions of the functionalized perylene bisimide $^{53,54}: 455 \mathrm{~nm}$ (S0-S2 electronic transition), 545 and $588 \mathrm{~nm}$ (S0-S1 electronic transition). ${ }^{55}$ The characteristic absorption red shifted to $458 \mathrm{~nm}$, $550 \mathrm{~nm}$ and $593 \mathrm{~nm}$ in compound TPPY due to the electron transfer from the pyridine to perylene unit. At the same time, the fluorescence spectra showed that the maximum emission band located at $620 \mathrm{~nm}$

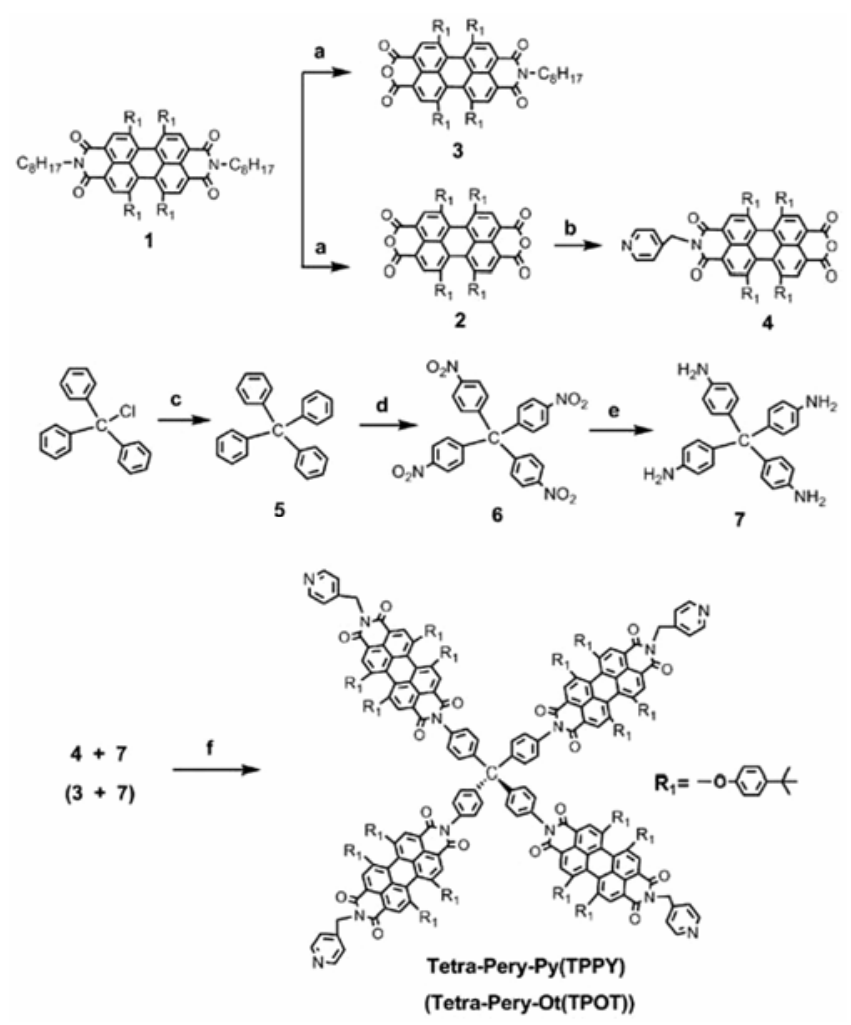

Scheme 1. Synthetic route of TPPY and TPOT. (a) $\mathrm{KOH}$, isopropyl alcohol, $\mathrm{H}_{2} \mathrm{O}$, reflux, $10 \mathrm{~h}$; (b) 4(aminomethyl)pyridine, imidazole, reflux, $2 \mathrm{~h}$; (C) aniline, $200^{\circ} \mathrm{C}, 5 \mathrm{~min}$, then, $\mathrm{HCl} / \mathrm{CH}_{3} \mathrm{OH}$, reflux, $10 \mathrm{~h}$; (d) nitric acid, $0^{\circ} \mathrm{C}$ to $\mathrm{RT}, 10 \mathrm{~h}$; (e) $\mathrm{NH}_{2} \mathrm{NH}_{2}, \mathrm{Pd} / \mathrm{C}, \mathrm{THF}$, reflux, $4 \mathrm{~h}$; (f) imidazole, toluene, reflux, $3 d$.

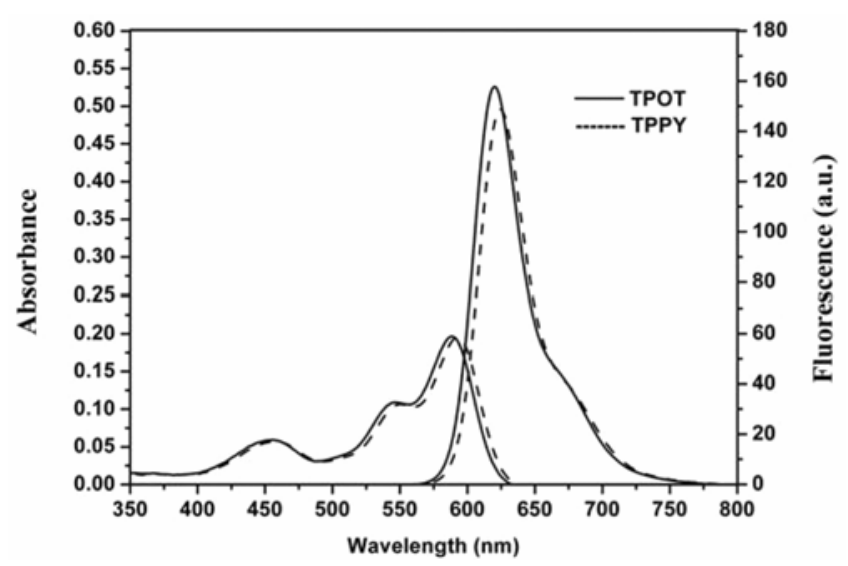

Figure 1. UV-Vis absorption and fluorescence spectra of ligand TPPY and its derivative TPOT $\left(1 \times 10^{-6} \mathrm{M}\right)$ in $\mathrm{CHCl}_{3}$. 
for compound TPOT, which red shifted to $624 \mathrm{~nm}$ with relative decrease on intensity in comparison with compound TPPY. Meanwhile, the films of the compounds of TPPY and TPOT emitted red fluorescence at $628 \mathrm{~nm}$ and $630 \mathrm{~nm}$, respectively (figure 2 ). This kind of compound can be useful as a potential red emission material.

The UV-Vis spectra of the ligand TPPY with different concentration (from $1 \times 10^{-6} \mathrm{M}$ to $1 \times 10^{-4} \mathrm{M}$ ) showed that the characteristic absorbance of TPPY had no change with the concentration increased (figure 3), which demonstrated that the tetrahedral structure of TPPY prohibited the $\pi-\pi$ stacking of perylene unit in toluene. Therefore, the selfassembly structure of Au NPs was only influenced by the structure of TPPY. Meanwhile, the minimum energy optimization of ligand TPPY was shown in figure S1 with the MM2 minimum energy method, which showed that the distance between optional two pyridines is about $3 \mathrm{~nm}$ (see the supporting information). We suggested that the aggregation of $\mathrm{Au}$ NPs was able to control by such special structure of ligand.

Table 1. Photophysical properties of TPPY and TPOT.

\begin{tabular}{lccc}
\hline & $\mathrm{UV} \lambda_{\max }(\mathrm{nm})$ & $\mathrm{FL} \lambda_{\max }(\mathrm{nm})$ & $\varphi_{\mathrm{F}}{ }^{a}$ \\
\hline TPOT & 588 & 620 & 0.90 \\
TPPY & 593 & 624 & 0.83 \\
\hline
\end{tabular}

${ }^{\mathrm{a}} N, N^{\prime}$-Di(2,6-diisopropylphenyl)-1,6,7,12-tetraphenoxyperylene-3,4,9,10-tetracarboxylic diimide (TPPI) as reference (fl ) 0.96 in $\left.\mathrm{CHCl}_{3}\right)^{48}$

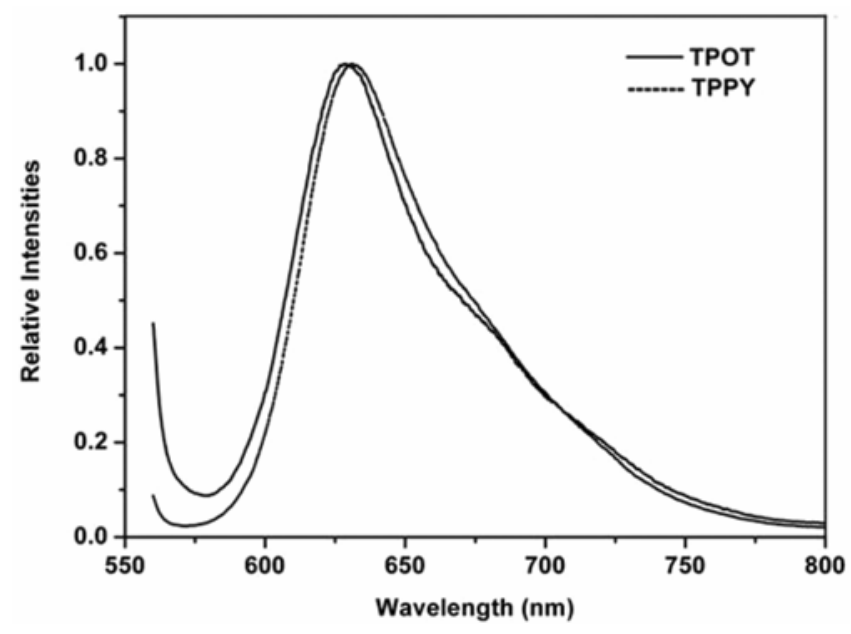

Figure 2. Normalized fluorescence spectra of compounds TPPY and TPOT in solid film.

\subsection{Self-assembly of TPPY with TOAB-capped Au NPs}

Fluorescence titration experiments were carried out in toluene. A solution of TOAB-capped Au NPs in toluene was titrated against a solution of ligand TPPY in toluene and the resultant TPPY fluorescence was monitored. As shown in figure 4, the fluorescence of TPPY was quenched as the Au NPs were added. The result showed that the interaction of the ligand with the Au NPs can lead to an effective energy transfer. ${ }^{47}$

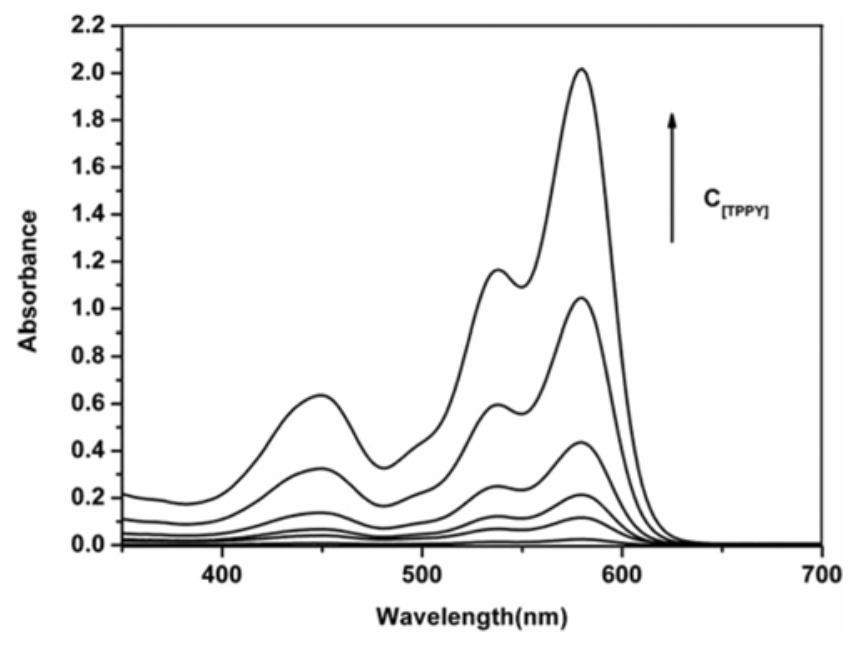

Figure 3. UV-Vis absorbance spectra of TPPY with different concentration $\left(1 \times 10^{-6}, 5 \times 10^{-6}, \quad 1 \times 10^{-5}\right.$, $2 \times 10^{-5}, 5 \times 10^{-5}, 1 \times 10^{-4} \mathrm{M}$, the width of cell is $0 \cdot 1 \mathrm{~cm})$.

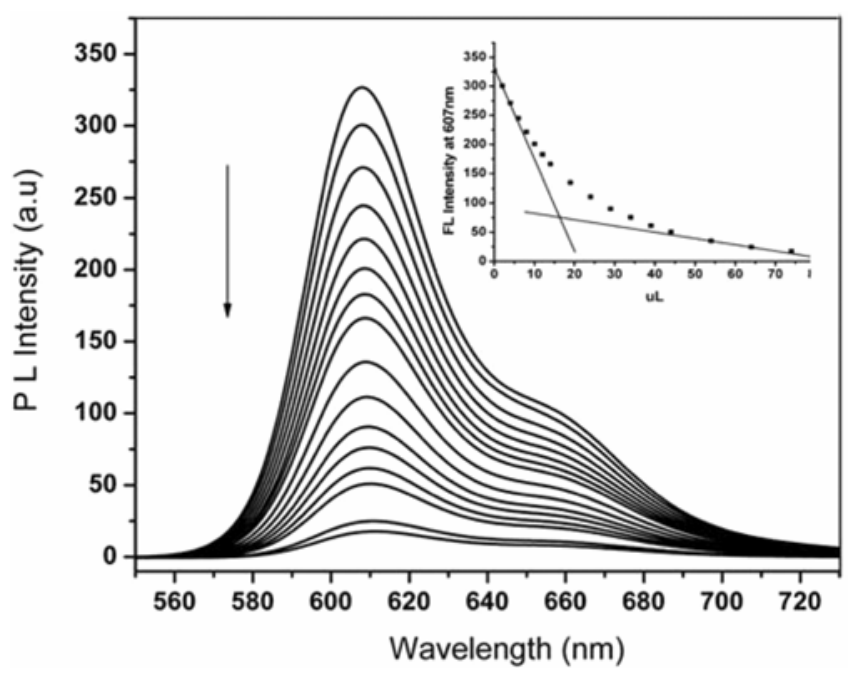

Figure 4. The fluorescence titration experiments of TPPY with the TOAB-capped AuNPs. $\lambda_{\mathrm{ex}}=550 \mathrm{~nm}$. The inset shows the PL intensity at $608 \mathrm{~nm}$ versus the volume $(\mu \mathrm{L})$ of Au NPs. 
As shown in figure 3, the special tetrahedral structure of TPPY prohibits the $\pi-\pi$ stacking interaction between the perylene units. The driving force for the self-assembly of TPPY with Au NPs is the coordination interaction which is weaker than the interactions of thiols with gold nanoparticles. This weak interaction would not only be affected by the ratio of the ligand and Au NPs but also affected by the concentration of the solution.

Optical spectra and microscopic data were used to monitor the self-assembly process of the ligand TPPY with the TOAB-capped Au NPs. When the concentration of Au NPs was $18.8 \mu \mathrm{M}$, a titration experiment was carried out by adding different concentration of ligand to the $\mathrm{Au} \mathrm{NPs}$. The surface plasmon (SP) absorption band (figure 5) of TOABcapped $\mathrm{Au}$ NPs decreased slightly and only red shifted $4 \mathrm{~nm}$ using a large excess of TPPY $(r \approx 2 k$, the definition of $r$, see the Supporting Information). This result showed that the interaction of TPPY with $\mathrm{Au}$ NPs was weak at the low concentration of the $\mathrm{Au}$ NPs. The TEM data also proved that result, which showed that the size of Au NPs $(\approx 5 \mathrm{~nm})$, before (figure 6a) and after (figure $6 \mathrm{~b}$ ) addition of an excess of TPPY, was nearly the same.

When the concentration of $\mathrm{Au}$ NPs was $0.47 \mu \mathrm{M}$, the TPPY can efficiently assemble with them. Optical spectra and microscopic data were used to monitor the self-assembly structures. UV-Vis absorption measurements were carried out in toluene, which showed TPPY concentration-dependent behaviour.

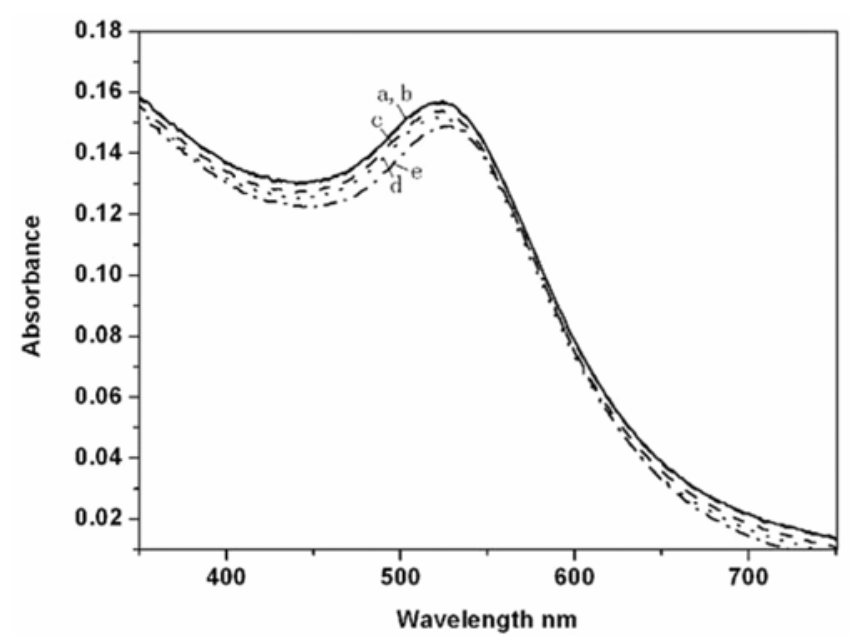

Figure 5. UV-Vis spectra of the Au NPs. (a) TOABcapped Au NPs (18.8 nM); (b) after adding $100 \mu \mathrm{L}, 10^{-4} \mathrm{M}$ TPPY; (c) after adding $200 \mu \mathrm{L}, 10^{-4} \mathrm{M}$ TPPY; (d) after adding $300 \mu \mathrm{L}, 10^{-4} \mathrm{M}$ TPPY; (e) after adding $400 \mu \mathrm{L}$, $10^{-4} \mathrm{M}$ TPPY.
The SP absorption band with a maximum at $\lambda=524 \mathrm{~nm}$ remained when the concentration of TPPY was $1.25 \times 10^{-5} \mathrm{M}(r=26 \cdot 6)$. As the concentration of TPPY increased, the SP absorption band of $\mathrm{Au} \mathrm{NPs}$ red shifted from $524 \mathrm{~nm}$ to nearly $740 \mathrm{~nm}$ (figure 7), indicating the efficient selfassembly of TPPY with TOAB-capped Au NPs.

The related TEM data were shown in figure 8 . For the low concentration of TPPY $\left(1.25 \times 10^{-5} \mathrm{M}\right)$, no obvious self-assembly behaviour was observed and the $\mathrm{Au}$ NPs with the diameter of nearly $5 \mathrm{~nm}$ were present (figure 8A). When the concentration of TPPY was $5 \times 10^{-5} \mathrm{M}\left(r=1.06 \times 10^{2}\right)$, the Au NPs were able to self-assemble into large scale clusters with average diameter nearly $50 \mathrm{~nm}$. Moreover, when the concentration of TPPY increased to $1 \times 10^{-4} \mathrm{M}\left(r=2 \cdot 13 \times 10^{2}\right)$, the observation of TEM showed that the cluster structure of Au NPs was not changed, but some of clusters began to aggregate (figure S2C). As the concentration increased to $2 \times 10^{-4} \mathrm{M} \quad\left(r=4.26 \times 10^{2}\right)$, the Au NPs clusters linked to each other forming a chain-like structure (figure 8C). As the concentration continuously increased to $5 \times 10^{-4} \mathrm{M}\left(r=10.6 \times 10^{2}\right)$, the Au NPs aggregated into sphere-like structure with an average diameter of nearly $200 \mathrm{~nm}$ (figure 8D). Unlike the aforementioned cluster structure, this sphere-like structure consisted of many tight-aggregated $\mathrm{Au}$ NPs. When the concentration of TPPY arrived at $1 \times 10^{-3} \mathrm{M}\left(r=2.13 \times 10^{3}\right)$, some fusions happened (figure S2E).

\subsection{The self-assembly mechanism of TPPY with TOAB-capped Au NPs}

According to the optical spectra and microscopic data, the aggregates of the TOAB-capped Au NPs could be controlled at a Au NPs concentration of $0.47 \mu \mathrm{M}$. When the TOAB molecules on the surface of Au NPs were displaced gradually by the pyridine ligands in TPPY, the self-assembly of Au NPs took place. When the concentration of the TPPY was $5 \times 10^{-5} \mathrm{M}$, TPPY displaced some of the TOAB molecules leading to the aggregation of $\mathrm{Au}$ NPs. However, in this concentration, the weak interactions could not induce a large aggregation but formed clusters consisting of many separated $\mathrm{Au}$ NPs. The reasons were as follows: (i) the big rigid structure of TPPY prohibited the tight-aggregation of separated Au NPs; (ii) and the charge repulsion of the unsubstituted TOAB molecules on the surface of 

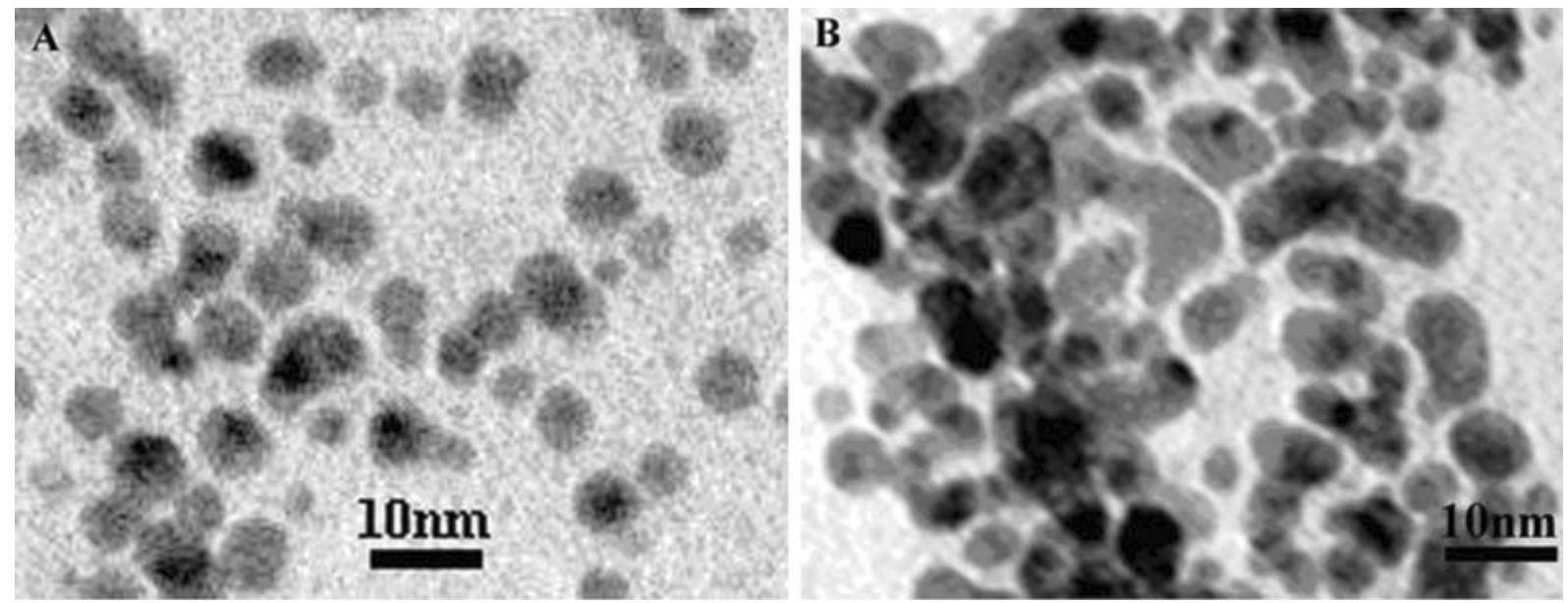

Figure 6. TEM images of (A) TOAB-capped Au NPs; (B) after the addition of ligand TPPY (400 $\mu \mathrm{L}$, $\left.10^{-4} \mathrm{M}\right)$.

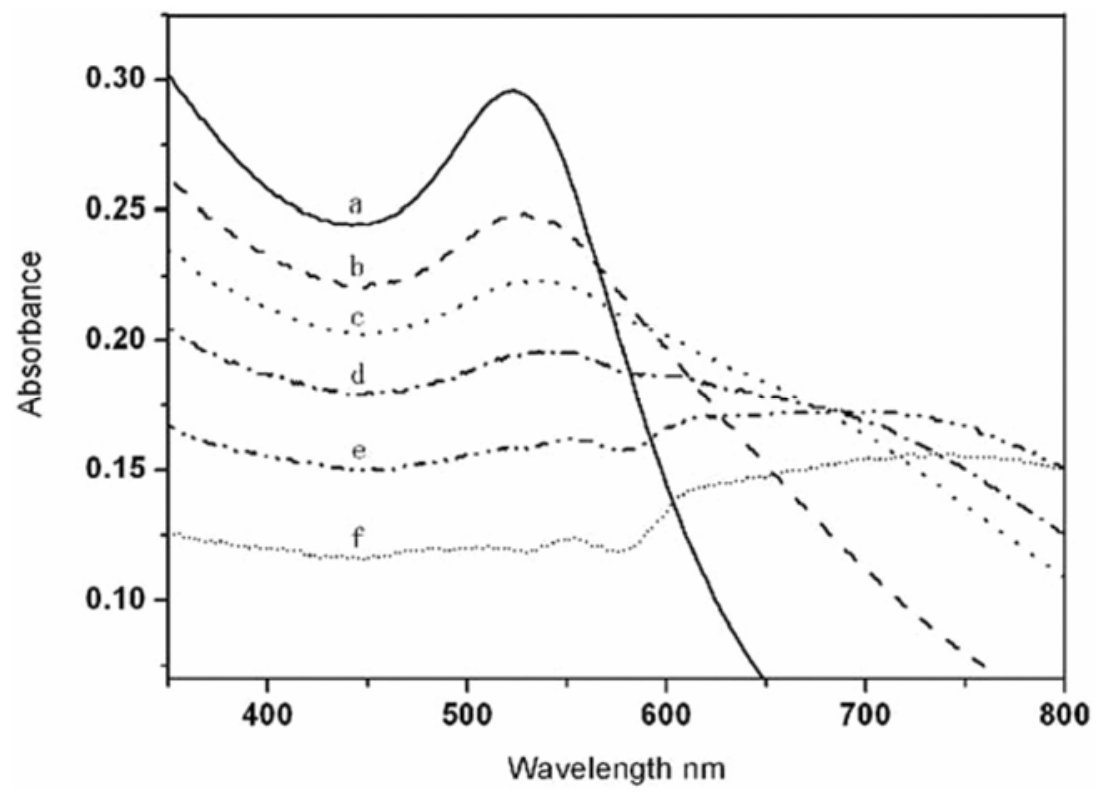

Figure 7. UV-Vis spectra of the Au NPs self-assemble with different concentration of TPPY. (a) Au NPs $(0.47 \mu \mathrm{M})$; (b) $[\mathrm{TPPY}]=5 \times 10^{-5} \mathrm{M}$; (c) $[\mathrm{TPPY}]=1 \times 10^{-4} \mathrm{M}$; (d) $[\mathrm{TPPY}]=2 \times 10^{-4} \mathrm{M}$; (e) $[\mathrm{TPPY}]=5 \times$ $10^{-4} \mathrm{M}$; (f) $[\mathrm{TPPY}]=1 \times 10^{-3} \mathrm{M}$ (the width of cell is $0.1 \mathrm{~cm}$ ).

$\mathrm{Au}$ NPs also prohibited the tight-aggregation of them. Continually increasing the concentration of ligand, more TOAB molecules were displaced by them. However, due to the large steric hindrance effect, the added TPPY exchanged the exterior TOAB molecules of the clusters preferentially. The former clusters linked to each other forming a chainlike structure when the concentration of TPPY was $2 \times 10^{-4} \mathrm{M}$. Adding a large excess of the ligand TPPY, the TOAB molecules on the surface of $\mathrm{Au}$ NPs were displaced by them thoroughly. Electro- static repulsion between the TOAB molecules was disappeared which led to tight aggregation of the separated $\mathrm{Au}$ NPs. In this condition, the former chain-like structure was destroyed, forming a sphere-like structure.

\section{Conclusions}

In conclusion, we have synthesized and characterized two novel tetrahedral molecules TPPY and its 

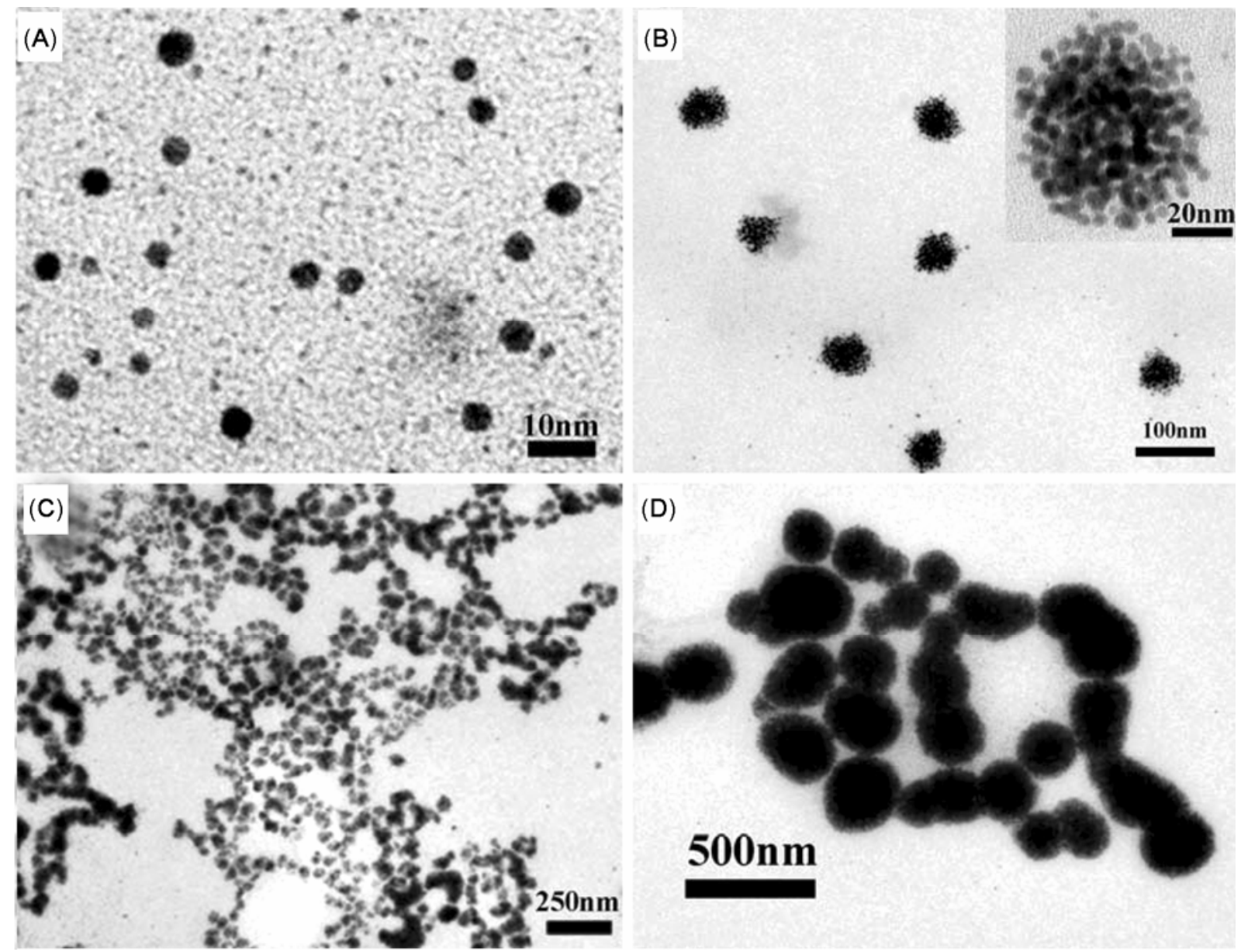

Figure 8. TEM images of Au NPs with different concentration of TPPY: (A) $1.25 \times 10^{-5} \mathrm{M}$; (B) $5 \times 10^{-5} \mathrm{M}$; the inset shows the high-magnification of a cluster; (C) $2 \times 10^{-4} \mathrm{M}$; (D) $5 \times 10^{-4} \mathrm{M}$.

derivative TPOT. The self-assembly of TPPY with $\mathrm{Au}$ NPs in toluene was also investigated, the results showed that the most effective assembly of TPPY and Au NPs could take place at Au NPs concentration of $0.47 \mu \mathrm{M}$. Meanwhile, in that concentration, the aggregation of Au NPs was controllable by changing the concentration of the ligand TPPY. Such organic-inorganic hybrid nanoscale materials of perylene capped Au NPs with control over the shape, bring new and exciting perspectives to photoand electronic-active materials and we are now pursuing their physical properties and potential applications.

\section{Acknowledgements}

This work was supported by the National Science Foundation of China (No. 20901063), the Open Research Fund of Key Laboratory for Green Chemical Process of Ministry of Education, Wuhan Institute of Technology under grant No. GCP200905, and the Science Research Fund of Wuhan Institute of Technology (No. 10092021).

\section{Supplementary information}

The figure of TPPY with the minimum energy simulation, the definition of $r$ and the original ${ }^{1} \mathrm{H}$ NMR, ${ }^{13} \mathrm{C}$ NMR, and MALDI-TOF spectra of all new compounds are provided in supplementary information (see www.ias.ac.in/chemsci).

\section{References}

1. Seybold G and Wagenblast G 1989 Dyes Pigm. 11 303

2. Kalinowski J, Marco P D, Fattori V, Giuletti L and Cocchi M 1998 J. Appl. Phys. 834242

3. Sadrai M, Hadel L, Sauers R R, Husain S, KroghJespersen K, Westbrook J D and Bird G R 1992 J. Phys. Chem. 967988

4. Gvishi R, Reisfeld R and Brushtein Z 1993 Chem. Phys. Lett. 213338 
5. O’Neil M P, Niemczyk M P, Svec W A, Gosztola D, Gaines G L and Wasielewski M R 1992 Science 257 63

6. Schlettwein D, Wöhrle D, Karmann E and Melville U 1994 Chem. Mater. 63

7. Xiao S Q, Li Y L, Li Y J, Yang C H, Liu H B, Ning B, Liu Y, Lu F S, Fan L Z, Zhuang J P, Li Y F and Zhu D B 2004 J. Phys. Chem. B108 16677

8. Li Y J, Wang N, He X R, Wang S, Liu H B, Li Y L, Li X F, Zhuang J P and Zhu D B 2005 Tetrahedron 611563

9. Dotcheva D, Klapper M and Müllen K 1994 Macromol. Chem. Phys. 1951905

10. Quante H, Greets Y and Müllen K 1997 Chem. Mater. 9495

11. Langhals H and Jona W 1998 Angew. Chem., Int. Ed. 37952

12. Gade L H, Williams C H R M, De Cola L, McPartlin M, Dong B and Chi L 2003 Angew. Chem., Int. Ed. 422677

13. Noma N, Tsuzuki T and Shirota Y 1995 Adv. Mater. 7647

14. Toshimitsu T, Hirota N and Noma N 1996 Thin Solid Films 273177

15. Liu X F, Zhu M, Chen S H, Yuan M J, Guo Y B, Song Y L, Liu H B and Li Y L. 2008 Langmuir 24 11967

16. Maye M M, Luo J, Lim I S, Han L, Kariuki N N, Rabinovich D, Liu T B and Zhong C J $2003 \mathrm{~J}$. Am. Chem. Soc. 1259906

17. Srivastava S, Frankamp B L and Rotello V M 2005 Chem. Mater. 17487

18. Huang H Y, Chen W F and Kuo P L 2005 J. Phys. Chem. B109 24288

19. Lin S, Li M, Dujardin E, Girard C and Mann S 2005 Adv. Mater. 172553

20. Lee H, Choi S H and Park T G 2006 Macromolecules 3923

21. Liu X F, Li C H, Xu J L, Zhu M, Guo Y B, Cui S, Liu H B, Wang S and Li Y L 2008 J. Phys. Chem. B112 10778

22. Lin S Y, Wu S H and Chen C H 2006 Angew. Chem., Int. Ed. 454948

23. Ipe B I, Yoosaf $\mathrm{K}$ and Thomas K G $2006 \mathrm{~J}$. Am. Chem. Soc. 1281907

24. Itoh H, Naka K and Chujo Y 2004 J. Am. Chem. Soc. 1263026

25. Liu J W and Lu Y 2005 J. Am. Chem. Soc. 12712677

26. He X R, Zhong Z F, Guo Y B, Lv J, Xu J L, Zhu M, Li Y L, Liu H B, Wang S, Zhu Y L and Zhu D B 2007 Langmiur 238815

27. Zheng N F and Stucky G D $2006 \mathrm{~J}$. Am. Chem. Soc. 12814278

28. Corma A, Serna P and García H 2007 J. Am. Chem. Soc. 1296358

29. Fendler J H 1996 Chem. Mater. 81616

30. Murray C B, Kagan C R and Bawendi M G 2000 Rev. Mater. Sci. 30545
31. Stellacci F, Bauer C A, Friedrichsen T M, Wensenleers W, Marder S R and Perry J W $2003 \mathrm{~J}$. Am. Chem. Soc. 125328

32. Imahori H, Fujioto A, Kang S, Hotta H, Yoshida K, Umeyama T, Matano Y and Isoda S $2005 \mathrm{Adv}$. Mater. 171727

33. Hasobe $\mathrm{T}$, Imahori $\mathrm{H}$, Kamat $\mathrm{P}$ V, Ahn $\mathrm{T}$ K, Kim $\mathrm{S}$ K, Kim D, Fujimoto A, Hirakawa T and Fukuzumi S 2005 J. Am. Chem. Soc. 1271216

34. Lv J, Zhao Y J, Li G X, Li Y J, Liu H B, Li Y L, Zhu D B and Wang S 2009 Langmiur 2511351

35. Li C H, Liu X F, Yuan M J, Li J B, Guo Y B, Xu J L, Zhu M, Lv J, Liu H B and Li Y L 2007 Langmiur 23 6754

36. Lv J, Jiang L, Li C H, Liu X F, Yuan M J, Xu J L, Zhou W D, Song Y L, Liu H B, Li Y L and Zhu D B 2008 Langmiur 248297

37. Li C H, Jiang L, Liu H B, Li Y L and Song Y L 2009 Chem. Phys. Chem. 102058

38. Ozawa H, Kawao M, Tanaka H and Ogawa T 2007 Langmuir 236365

39. Christian R H, Fredrik W, Kasper M P, Renu R, Suresh V and Thomas B 2008 Langmuir 243905

40. Deng F J, Yang Y Y, Hwang S H, Shon Y S and Chen S W 2004 Anal. Chem. 766102

41. Hisashi F and Hidetaka N 2001 Langmuir 176393

42. Anne K, Riikka L, Heli L, Nikolai V T and Helge L 2008 J. Phys. Chem. C112 10316

43. Herrikhuyzen J V, Janssen R A J, Meijer E W, Meskers S C J and Schenning A P H J $2006 \mathrm{~J}$. Am. Chem. Soc. 128686

44. Daniel M C and Astruc D 2004 Chem. Rev. 104293

45. Thomas K G and Kamat P V 2003 Acc. Chem. Res. 36888

46. He X R, Zhong Z F, Guo Y B, Lv J, Xu J L, Zhu M, Li Y L, Liu H B, Wang S, Zhu Y L and Zhu D B 2005 Adv. Mater. 172811

47. Andres R P, Bielfeld J D, Henderson J I, Janes D B, Kolagunta V R, Kubiak C P, Mahoney W J and Osifchin R G 1996 Science 2731690

48. Chen S and Murray R W 1999 J. Phys. Chem. B103 9996

49. Liu X F, He X R, Jiu T G, Yuan M J, Xu J L, J. Lv, Liu H B and Li Y L 2007 Chem. Phys. Chem. 8906

50. Ren J, Zhao X L, Wang Q C, Ku C F, Qu D H, Chang C P and Tian H 2005 Dyes Pigm. 64193

51. Würthner F, Sautter A and Schilling J $2002 \mathrm{~J}$. Org. Chem. 673037

52. Li Y J, Wang N, Gan H Y, Liu H B, Li H, Li Y L, He X R, Huang C S, Cui S, Wang S and Zhu D B 2005 J. Org. Chem. 709686

53. Ford W E and Kamat P V 1987 J. Phys. Chem. 91 6373

54. Ford W E, Hiratsuka H and Kamat P V 1989 J. Phys. Chem. 936692

55. Liu D, De F S, Cotlet M, Stefan A, Wiesler U M, Herrmann A, Grebel-Koehler D, Qu J, Müllen K and De S F C 2003 Macromolecules 365918 